\title{
Mechanical hydraulic control of water turbine based on improved PID algorithm
}

\author{
Lu Xing-Hua ${ }^{1, a}$ \\ ${ }^{1}$ HuaLi College Guangdong University of Technology, Guangdong Guang Zhou Zhengcheng \\ 511325, China \\ a44680189@qq.com
}

Keywords: water turbine; hydraulic control; improved PID control algorithm

\begin{abstract}
The problem of accurate control of water turbine mechanical hydraulic is researched. Water turbine hydraulic control system is a complicated system with strong time-varying and nonlinear. In the control process, it is easy to be interfered with the external environment, the control accuracy is reduced, and it cannot meet the actual demand of turbine operation process. Therefore, a mechanical hydraulic control method of water turbine is proposed based on improved PID control algorithm. PID controller is designed, in the controller design process, it needs to set up PID control differential equation, the particle swarm algorithm and PID control algorithm are fused, and design method of improved PID controller is obtained, the controller is applied in the water turbine hydraulic mechanical control, the simulation results show that the new algorithm can greatly improve the control precision, it has strong adaptability and robustness, it meets the actual demand of water turbine.
\end{abstract}

\section{Introduction}

With the worldwide energy shortage, how to make use of water resources has become an important topic in the research field of energy. Water hydraulic turbine is an important mechanical equipment, it is used in development of water resources mining[1-3]. In the process of water turbine application, the hydraulic control plays a vital role. Therefore, the mechanical hydraulic control method of water turbine has already become the core problem in the field of energy research, and it has received great attention from the scholars. At present, the main mechanical hydraulic control methods of water turbine include mechanical turbine hydraulic control method, ant colony fusion algorithm based on Genetic Algorithm, and hydraulic turbine hydraulic control method, turbine hydraulic control method based on PID control algorithm, and so on. Among them, is the mechanical hydraulic control method of water turbine based on PID control algorithm is widely used in application. Due to mechanical turbine hydraulic control method has a very broad space for development, so it has huge development potential and broad prospects for development [4,5].

\section{Principle of mechanical hydraulic control method of water turbine based on improved PID algorithm}

\section{A Design of PID controller}

In the process of mechanical hydraulic control of water turbine, PID controller needs to be designed, so as to realize the machinery control of hydraulic turbine, the PID controller consists three different parts as proportional, integral and differential part, the performance of the turbine machinery hydraulic controller is mainly composed of a control parameter, $K_{p}$, the values of $K_{i}$ and $K_{d}$ are determined. Assuming the control parameter values are determined in a reasonable interval, then the hydraulic turbine mechanical hydraulic control error can reach to the minimum value, it can meet the actual demand of water turbine. The differential equation of turbine mechanical hydraulic control is shown as follows: 


$$
u(t)=K_{p} e(t)+K_{i} \int_{0}^{t} e(t) d t+K_{d} \frac{d e(t)}{d t}
$$

In the formula, $u(t)$ is used to describe the output signal of turbine machinery hydraulic PID controller for hydraulic turbine hydraulic control, $e(t)$ is the difference value between the process of feedback signal and the input signal to the controller, $K_{p}$ is the proportional coefficient of PID controller, $K_{i}$ is the integral coefficient of controller, $K_{d}$ is the differential coefficient of the controller.

\section{B Improved PID controller design}

The particle swarm algorithm and PID controller are combined, it can avoid the disadvantages of the conventional PID controller, improve the control precision, the principle is expressed as follows:

Particle swarm optimization algorithm is a kind of method that simulates the foraging behavior of animal collective, the algorithm can complete the decision, and the algorithm is a global optimization algorithm. In application process of the particle swarm algorithm, individual extremum can be described by $P_{t}$, the groups extremum can be described by $G_{t}$. The extreme values as above can be used to update space position and velocity of individuals and groups of particles correspondingly. The corresponding evolution equation is shown as follows:

$$
\begin{aligned}
& V_{t+1}=w V_{t}+c_{1} r_{1}\left(P_{t}-X_{t}\right)+c_{2} r_{2}\left(G_{t}-X_{t}\right) \\
& X_{t+1}=X_{t}+V_{t+1}
\end{aligned}
$$

In the above formula, $w$ can be used to describe the inertia weight coefficient in the particle operation process, $\mathrm{c} 1$ and $\mathrm{c} 2$ can be used to describe the particle speed update parameters; $\mathrm{r} 1$ and $\mathrm{r} 2$ can be used to describe the random number in the range of $[0,1]$.

In order to improve global optimization ability of improve PID control algorithm in mechanical hydraulic turbine hydraulic control process, it needs to use the corresponding linear weight calculation formula as:

$$
w=w_{\text {start }}-\frac{t\left(w_{\text {start }}-w_{\text {end }}\right)}{T}
$$

In the above formula, $w_{\text {start }}, w_{\text {end }}$ can respectively show the weights and iterative processing times, it is used to describe the inertia weight in the original state of the maximum value under the condition of weight, $\mathrm{t}$ can be used to describe the iterative processing times at present, $\mathrm{T}$ can be used to describe the maximum number of iterative processing.

In the process of mechanical hydraulic control of water turbine, use the following formula to calculate control fitness function:

$$
f=\left(\frac{1}{T} \int_{0}^{T}\left|\ddot{x}_{2}\right|^{2} d t\right)^{1 / 2}
$$
ideal.

In the above formula, the fitness value is smaller, on behalf of the controller performance is more

According to the method described above, particle swarm algorithm and PID control algorithm can be combined, the improved PID controller is obtained, the detailed process of control is expressed as follows:

(1) Initialize the particle swarm population, assignment is obtained for each particle, set the control parameters to improve the PID controller, and the control parameters of the improved PID controller is taken as the control variable.

(2) The fitness of turbine machinery hydraulic control is calculated.

(3) According to the fitness value, determine whether to stop the process of iterative processing, assuming it meets the fitness requirements, then stop the iteration, otherwise, continue to the particle update processing, return to step (2). 


\section{System simulation and analysis}

In order to verify the validity of this algorithm, it needs for a simulation experiment, the traditional algorithm and the new algorithm are compared in the simulation, the traditional algorithm and the new algorithm are applied in the machinery hydraulic control of water turbine. In the $100 \%$ load and $70 \%$ load, different control algorithms are used for step change experiments, and the controller output curves of different control algorithms are shown in Figure 1 and Figure 2.

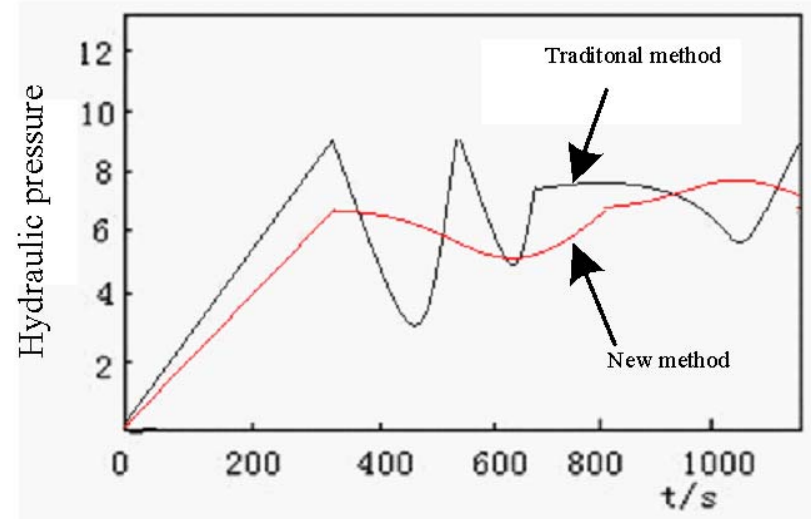

Figure 1 Control step response output in 100\% load

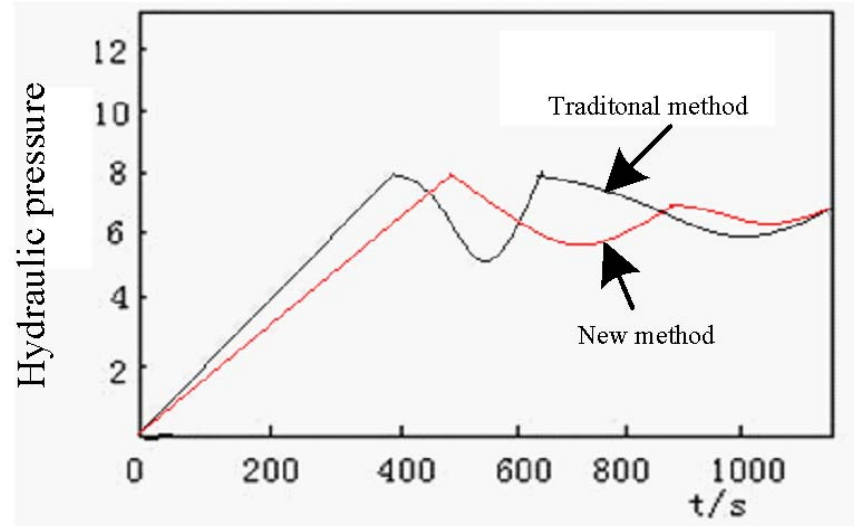

Figure 2 Control step response output in $70 \%$ load

According to the above experimental results, it shows that this new algorithm is used in turbine machinery hydraulic control, when the load is relatively high, the effect of control may still be able to obtain the ideal result, in $70 \%$ load conditions, the control effect of traditional algorithm is relative ideal, but in the case of high load, the control results cannot meet the turbine machinery hydraulic control demand, it demonstrates the advantages of the proposed algorithm.

In the course of the experiment, the control precision data are analyzed, and the following table is obtained.

Table 1 Control precision comparison

\begin{tabular}{|c|c|c|c|c|}
\hline \multirow[b]{2}{*}{$\begin{array}{l}\text { Number } \\
\text { experiments }\end{array}$} & \multicolumn{2}{|c|}{ Control precision in $100 \%$ load $(\%)$} & \multicolumn{2}{|c|}{ Control precision in $70 \%$ load $(\%)$} \\
\hline & $\begin{array}{l}\text { O1 } \\
\text { Traditional } \\
\text { algorithm }\end{array}$ & New algorithm & $\begin{array}{l}\text { Traditional } \\
\text { algorithm }\end{array}$ & New algorithm \\
\hline 1 & 89 & 97 & 98 & 98 \\
\hline 2 & 92 & 98 & 97 & 97 \\
\hline 3 & 88 & 97 & 98 & 98 \\
\hline 4 & 94 & 97 & 98 & 98 \\
\hline 5 & 93 & 96 & 96 & 99 \\
\hline 6 & 91 & 98 & 96 & 98 \\
\hline 7 & 92 & 97 & 95 & 97 \\
\hline 8 & 94 & 97 & 96 & 98 \\
\hline 9 & 90 & 98 & 94 & 99 \\
\hline 10 & 92 & 96 & 97 & 96 \\
\hline
\end{tabular}


Based on the data in the table, it can be learned that the new algorithm can improve the control accuracy in the machinery hydraulic control of water turbine, it can meet the actual demand of turbine machinery hydraulic control, so as to obtain the ideal control effect.

\section{Conclusions}

In this paper, a mechanical hydraulic control method of water turbine is proposed based on improved PID control algorithm. PID controller is designed, in the controller design process, it needs to set up PID control differential equation, the particle swarm algorithm and PID control algorithm are fused, and design method of improved PID controller is obtained, the controller is applied in the water turbine hydraulic mechanical control, the simulation results show that the new algorithm can greatly improve the control precision, it has strong adaptability and robustness, it meets the actual demand of water turbine.

\section{Acknowledgments}

Foundation item: Innovative Experimental Area of Training of Electronic. Information Talents in Independent Colleges(OfficialLetter No. [2012]204, The Higher Education Department of Guangdong Province)

\section{References}

[1] Rao Yutai,Yang fan. Network Intrusion Stir the Network Instability Control Methods of the Research[J]. BULLETIN OF SCIENCE AND TECHNOLOGY, 2014,30(1): 185-188.

[2] LI Feng, WU Chun- ming. Research on Prevention Fluctuation Control method of Network Intrusion Based on Energy Management[J]. Computer simulation, 2013,30(12): 45-48, 335.

[3] WANG Rui, MA Yan. DOA Estimation of Wideband Linear Frequency Modulated Pulse Signals Based on Fractional Fourier Transform[J]. Acta Armamentarii, 2014,35(3):421-427.

[4] XU Xiao-bin, ZHANG Guang-wei, SUN Qi-bo, et al. Precision Configurable Data Aggregation Algorithm in WSNs[J]. ACTA ELECT R ONICA SINICA, 2014, 42(6):1205-1209.

[5] PENG Li-ying. Traffic Data Anti Step Fusion Algorithm Based on Improved Sliding Mode Disturbance Control Rule[J]. Control Engineering of China, 2014,21(4): 515-519. 